\title{
Challenges of using collaborative methods in surveying political trust in Haiti
}

Han Dorussen, Zorzeta Bakaki and Athena R. Kolbe

Forthcoming in PS: Political Science \& Politics

Han Dorussen is a professor in the Department of Government at the University of Essex. His research interests are in peacekeeping and the governance of post-conflict societies. He maybe reached at hdorus@essex.ac.uk.

Zorzeta Bakaki is a senior lecturer in the Department of Government at the University of Essex. Her research interests are the qualitative and quantitative analysis of conflict management and resolution and environmental politics. She may may be reached at zbakak@essex.ac.uk.

Athena R. Kolbe is assistant professor in the School of Social Work at the College of Health and Human Services at the University of North Carolina, Wilmington. Her research interests are human rights, needs assessment, and international social work, with a particular focus on Haiti. She may be reached at kolbea@uncw.edu

\section{Introduction}

The introduction to this Symposium highlights that collaborative methods (CM) invite "people affected by the research puzzle [...] to participate in concept formation and methodological decision-making, regardless of whether the methods are quantitative or qualitative, or positivist or interpretivist." (Firchow and Gellman 2021, 1-2, emphasis added). There are, however, practical issues limiting opportunities for meaningful collaboration with participants in large-N surveys. The collaboration may not be as thorough and meaningful as in smaller- 
sample surveys due to time and accessibility constraints. Here, we focus on how these limitations become even more apparent when fielding a survey in a politically unstable environment. Practical constraints and political volatility made it unfeasible for us to use $\mathrm{CM}$ in the implementation of our survey of political trust in Haiti, but in various ways we worked 'with' rather than 'on' local participants. Below, we discuss how collaboration was achievable and ultimately mattered. The highly uncertain political environment led us to rely on a Haitian research team to better evaluate local understanding of trust and to effectively design our study. Collaboration with the Haitian researchers helped us to address the idiomatic language, norms and cultures of local communities as well as variation in local awareness of peacebuilding organizations.

In the autumn of 2019, we fielded a survey in Haiti with the aim to examine trust among Haitians in external organizations such as the United Nations (UN) and international nongovernmental organizations (INGOs) as contrasted to local community organizations (LCOs) and local churches. Haiti has been flooded with foreign intervention following political upheaval in the 1990s and even more so after the devastating earthquake in 2010. The failures of foreign interventions in Haiti have been documented extensively, but little is known about how Haitians trust - or distrust - foreign organizations in contrast to local organizations. Collaboration with Haitians is clearly essential to deliver the local perspective that our study aimed for.

To measure what political trust means for Haitians, CM proposes to involve participants to define criteria and indicators that are accurate, complete and relevant for them. When implementing a large-N survey, in practice such involvement requires multiple iterations; for example, initial collaboration via focus group meetings to design the survey to be fielded 
subsequently. ${ }^{1}$ A highly uncertain and volatile political environment, however, risks framing the evaluation of political trust and to prime responses. To explain our rationale for not directly involving the survey participants in our study via CM, we illustrate how political trust is shaped in Haiti via positive and negative framing. Questions about political trust prime respondents to give negatively rather than positively worded responses indicating that participants are fundamentally affected by the instability in the country. Apart from creating obvious practical problems, (political) instability thus also undermines the collaborative measurement of trust. Therefore, in our case the applicability of $\mathrm{CM}$ for large-scale population surveys remained limited.

\section{Fielding the survey}

When researchers investigate regions that are unfamiliar to them, the knowledge and experience of local research teams is essential (Asiamah, Awal, and MacLean 2021). We relied on the long-standing cooperation between Athena Kolbe and a team of Haitian social workers and graduate students. Athena has long experience in organising surveys in Haiti. The Haitian research team provided valuable expertise in conducting social science surveys in Haiti. We provided the team with a thorough background of our study, while Athena was responsible for their training in terms of interviewing and sampling strategies. The Haitian team provided valuable local insights that we would be unable to grasp otherwise. We designed the survey questionnaire, defined the sampling frame and secured ethical approval. These tasks reflect both technical expertise and practical consideration, but also our broader theoretical interest in the study. Ultimately, we did not simply want to measure trust but to understand it as related to factors affecting levels of trust as well as possible implications of (lack of) trust. 
Collaboration with Haitian researchers mattered in a number of ways. First, the Haitian research team translated the survey instrument from English to Haitian Creole, and in the process helped to refine the question wordings. Second, local knowledge was vital to get a truly representative sample. Poor infrastructure and security concerns often limit and bias the access of Western researchers. Third, they suggested examples of LCOs and INGOs to be used in the survey. ${ }^{2}$ Local knowledge enabled them to identify organizations that were sufficiently known across Haiti, and to avoid naming organizations that had been embroiled in particular scandals. Mentioning the latter would have introduced bias by priming the responses on these scandals and may have left the wrong impression that the survey was part of a public relations effort. Finally, discussions with Haitian researchers convinced us to extend the number of indicators of trust. The team suggested adding indicators that they considered as relevant and fitting to local conditions.

\section{Challenges of CM when framing trust}

CM builds on the idea that reliance on local understanding increases the validity of one's research. Trust does not always have a similar meaning, and Haitians probably use different, context-specific indicators for trust. The perceptions, experiences with and expectations of a particular organization determine not only how much respondents trust that organization but also their criteria or indicators for trust.

Reflecting our theoretical understanding of trust as relational, the survey was designed to allow for comparisons within the Haitian population (as trustors) across different types of organizations (as trustees). Accordingly, appropriate indicators of trust had to balance shared understanding across Haiti, but also differentiation between trustors - variation among Haitians in their propensity to trust - and differences in perceived trustworthiness - variation across the 
different peacebuilding organizations. Therefore, simply asking about trust (konfyans in Creole) in an organization like the UN may not be informative. The Haitian understanding of what it means to trust an organization may correspond imperfectly with our - Western or theoretical - conceptualization. Firchow $(2018,109)$ argues for the importance of localized and contextual indicators when people describe peace in their life. For similar reasons, Flores (2021) proposes to develop Everyday Democracy Indicators. At the same time, highly finegrained or localized indicators are unlikely to represent the broader set of indicators relevant across Haiti. The promising iterative process as outlined by Levy and Firchow (2021) was in our cases infeasible because of budget and time constraints due to the volatile environment. There is a need to balance local and more universal indicators, but also to carefully consider how accurately collaborators - in our case, the Haitian researchers - represent the population of the study - Haitians in general. Our large-N survey of Haitians required a medium level of abstraction in measuring the central concept of trust balancing contextual indicators with a more universal extension (Sartori 1970, 1044). Also, our purpose here was to have the absolute control of the survey instrument to ensure that the questions asked pertained to the framing literature of trust to peacebuilding organization. Besides, since trust is multi-dimensional (Hardin 2002; Mayer, Davis, and Schoorman 1995), it matters to understand on what indicators respondents base their trust when evaluating a particular organization.

Moreover, positive or negative primes are likely to produce different indicators. e.g., reliability draws attention to the possible benefits an organization may bring, while corruption emphasizes losses. These effects result from equivalency framing which presents "the same critical information in either a positive or a negative light" and has been shown to affect individual perceptions (Levin, Schneider, and Gaeth 1998, 150). We expect that negative wording or frames prime trust perceptions more strongly by means of direct and indirect 
mechanisms. They do so directly because negative words - such as corruption and arrogance - prime on losses or on what organizations failed to deliver, where losses generally provoke stronger reactions. Indirect effects occur because traumatic experience of a conflict generally leads to low levels of trust in post-conflict societies such as Haiti (Hutchison and Johnson 2011). Experiencing substantial violence increases the risk that people perceive the state and other institutions as unable to provide security (De Juan and Pierskalla 2016).

We recognize the value of $\mathrm{CM}$ to identify nuanced experiences from local people reflecting concerns or feelings that cannot adequately be tackled in a survey instrument designed solely by the researchers. Since conflict is arguably an explanatory factor of trust, any measurement of trust involving collaboration with participants experiencing conflict will be biased towards negative indicators of trust. In conflict or highly volatile 'post'-conflict environments, it is challenging to directly involve CM because political trust not only tends to be low but respondents are only more responsive to negative indicators of trust, generating participants' bias in the study. This means that negative wording has a higher impact in post-conflict societies due to the pre-existing negativity of the traumatic experience. Negative wordings also prime respondents on negative, possibly even traumatic experiences and lower levels of trust accordingly.

\section{Evidence from Haiti}

Our survey instrument was implemented nationwide across Haiti amidst a deteriorating political situation. Approximately 2,000 respondents were probed about their perceptions of international and local institutions with a focus on political trust. We used different survey items to examine how wording affects the perception of political trust. Respondents were also 
asked about their overall experience with international and local organizations as well as how they felt about the current situation in Haiti (Dorussen, Bakaki, and Kolbe 2021).

The use of negatively or positively worded survey items can identify whether this aspect of survey design affects how people report political trust. Participants were asked about four different types of organizations (UN, INGOs, LCOs, and local churches) that operate across Haiti and to associate them with different words or short characterizations. About $98 \%$ of our sample was aware of the international organizations - i.e., UN, Action Aid, Save the Children - and local organizations - i.e., Fonkoze, Fokal, local churches - that we provided as examples. Also, $45 \%$ noticed some international institution working in the area, and $94 \%$ noticed a local institution in their region.

Participants received the survey questions and answered items in random order without any indication what we considered positive or negative wordings. They were asked what words 'best describe' each organization and they could select multiple items for each organization. We included sixteen positive items next to four negative items. The considerably larger number of positive items actually provides a hard test for our study since it essentially means that we could have obtained more answers for positive wordings. In effect, the structure and the wording of the questions give considerable freedom to respondents to indicate what particular aspects of trust they deem relevant for a specific organization. ${ }^{3}$

The first four items in table 1 are the ones we classify as negative wordings and the remaining ones are the positive wording items. Table 1 further ranks the words based on the frequency respondents associated them with a particular organization from highest to lowest frequency. We find that negative words like corrupt and arrogant are most commonly associated with all 
types of organizations; in particular, local churches and the UN are perceived as corrupt. Local churches are less commonly seen as arrogant compared to other types of organizations. INGOs are more often perceived as unpredictable, while local community organizations are more commonly seen as incapable.

[Place table 1 here]

Respondents are more inclined to ascribe positive wording to local community organizations. LCOs are perceived as representing Haitians, respecting Haitian autonomy and being approachable, where the differences can be quite stark - e.g., $66.15 \%$ agree that local community organizations respect Haitian autonomy, while only about $1 \%$ agrees that this applies to the UN. The only positive wording regularly associated with the UN is competent, where $30.06 \%$ describe the UN as competent compared to $12.29 \%$ for INGOs and less than $10 \%$ for LCOs and local churches. INGOs and local churches are associated with communicating effectively and respondents more often describe them as reliable compared to the UN and LCOs. Haitians are thus primed towards negative wordings reflecting lack of trust in foreign organizations but also disillusionment with local organizations.

To compare the general preference for positive and negative wordings, we generate indices for the positive and negative wording survey items for each organization. We then calculate the relative frequency by which respondents selected the provided survey wording: the number of times a positive or negative wording has been chosen divided by the total number of positive or negative wordings. When describing the UN, the results show that respondents selected on average only about $3 \%$ of the positive wordings, but, on average, more than $40 \%$ of the negative wordings available to them. When describing INGOs, they selected on average $8 \%$ of the 
positive wordings and on average $47 \%$ of the negative wordings available to them. Respondents selected more positive wordings when thinking of LCOs on average at $23.5 \%$ and on average about $31 \%$ of the negative wordings. When referring to local churches in Haiti our respondents selected $11 \%$ of the positive wordings and on average about $30 \%$ of the negative wording items. As shown in figure 1, these preferences significantly differ across most organizations presented as the bars of the confidence intervals do not overlap. The only exception is that negative wording for LCOs and local churches do not significantly differ. Even though respondents have negative feelings about all organizations, they report the strongest negative reaction to INGOs.

[Place figure 1 here]

\section{Conclusions}

The Everyday Peace Indicators (EPI) research approach (Firchow 2018) advocates the use of locally derived evaluation frames, and to rely on local stakeholders and respondents to identify indicators of (dis)trust. It proposes to use CM initially with local stakeholders via focus group meetings. It is our intention to incorporate focus group discussions in future research in order to allow for direct engagement with the local community, and eventually offer a thorough understanding of positive and negative framing of political trust. Participatory bias will be limited in selective focus groups with stakeholders who are better informed on the issue at stake. On the other hand, focus groups offer qualitative information that also have limitations in terms of generalizations even within the Haitian population given that it is a very diverse, yet small country. 
We relied on the expertise of the local Haitian research team to refine our research design. This helped us to obtain comprehensive and accurate information on political trust as relevant for the general Haitian population. The survey provides substantial evidence of the sources of trust (and distrust) in the large-scale population survey. Negative wordings provoke the strongest responses, but there is also notable variation in the choice of positive wordings across organizations, e.g., competent for the UN and respecting Haitian autonomy for LCOs. We would have not been able to obtain such findings with a smaller group of participants or directly collaborated with participants largely affected by the research question.

The contributions to this symposium illustrate how CM can be applied across a variety of methodological approaches. Collaboration with the people affected is also relevant and possible in population surveys but it poses some unique challenges. First of all, there will be more heterogeneity among the research population. For practical reasons, $\mathrm{CM}$ will only be able to engage with a relatively small group of participants. It is not only more difficult to capture the full heterogeneity with a small subset of participants, it is also key that the participants in $\mathrm{CM}$ are not a biased representation of the full population. The team of Haitian researchers upon whom we relied are obviously not a random sample of the Haitian population, but they have valuable knowledge and experience about doing (survey) research in Haiti. This is an important and relevant trade-off. If time and budget had permitted, applying EPI in multiple places could have identified a variety of relevant indicators which would have been interesting indeed (Levy and Firchow 2021). Potentially, EPI would have been more reflective of different experiences than the Haitian research team. Secondly, in important ways, our research population will also change over time. Temporal heterogeneity is particularly important in political volatile situations such as Haiti and causes problems when there is a need to scale up (Levy and Firchow 2021) when, for example, indicators identified by focus groups may no longer be appropriate 
when the larger survey is fielded. Thirdly, concepts are not theory-free, as illustrated by our finding that political instability as experienced by participants biases their preferred measures of trust. This does not invalidate the use of CM. In contrast, it highlights the necessity to remain aware of the risks of priming respondents and framing survey questions.

\section{References}

Asiamah, Gildfred, Mohammed S. Awal, and Lauren MacLean. 2021. "Collaboration for Designing, Conceptualizing and (Possibly) Decolonizing Research in African Politics.” PS: Political Science and Politics.

Bruine De Bruin, Wändi, Martine Baldassi, Bernd Figner, Baruch Fischhoff, Lauren Fleishman, David Hardisty, Eric Johnson et al. 2011. "Framing effects in surveys: How respondents make sense of the questions we ask." In Perspectives on Framing, ed. Gideon Keren, 303-25. New York: Psychology Press.

De Juan, Alexander, and Jan Henryk Pierskalla. 2016. "Civil war violence and political trust: Microlevel evidence from Nepal." Conflict Management and Peace Science 33 (1): 6788.

Dorussen, Han, Zorzeta Bakaki, Athena Kolbe. 2021. "Replication Data for: Challenges of using collaborative methods in surveying political trust in Haiti." https://doi.org/10.7910/DVN/D6W8W1, Harvard Dataverse, DRAFT VERSION, UNF:6:fTwCFRIX/Xkpm6P32JZIqw==[fileUNF].

Firchow, Pamina. 2018. Reclaiming everyday peace: Local voices in measurement and evaluation after war. Cambridge: Cambridge University Press.

Firchow, Pamina, and Mneesha Gellman. 2021 "Collaborative Methodologies: Why, For Whom and How?" PS: Political Science \& Politics. 
Flores, Thomas. 2021. "The Everyday Democracy Indicators? How the Study of Democracy Illuminates the Value (and Challenges) of Collaborative Methodologies." PS: Political Science \& Politics.

Hardin, Russell. 2002. Trust and trustworthiness. New York: Russell Sage Foundation.

Hutchison, Marc L., and Kristin Johnson. 2011. "Capacity to trust? Institutional capacity, conflict, and political trust in Africa, 2000-2005." Journal of Peace Research 48 (6): $737-52$.

Levin, Irwin, Sandra Schneider, and Gary Gaeth. 1998. "All frames are not created equal: A typology and critical analysis of framing effects." Organizational behavior and human decision processes 76 (2): 149-88.

Levy, Naomi, and Pamina Firchow. 2021. "Measuring Peace from the Bottom Up with the Pasto Indigenous Group in Nariño, Colombia.” PS: Political Science \& Politics.

Mayer, Roger C., James H. Davis, and F. David Schoorman. 1995. “An Integrative Model of Organizational Trust.” The Academy of Management Review 20 (3): 703-34.

Sartori, Giovanni. 1970. "Concept Misinformation in Comparative Politics.” American Political Science Review 64 (4): 1033-54. 


\begin{tabular}{|c|c|c|c|c|}
\hline & $\begin{array}{l}\text { United } \\
\text { Nations }\end{array}$ & $\begin{array}{c}\text { International } \\
\text { NGOs }\end{array}$ & $\begin{array}{l}\text { Local } \\
\text { Community } \\
\text { Organizations }\end{array}$ & $\begin{array}{c}\text { Local } \\
\text { Churches }\end{array}$ \\
\hline Corrupt (Kowonpi) & 74.73 & 57.73 & 43.83 & 95.17 \\
\hline Arrogant (Awogan) & 67.74 & 59.99 & 42.37 & 16.86 \\
\hline Unpredictable (Enprevizib) & 17.07 & 56.82 & 10.08 & 2.78 \\
\hline Incapable (Enkapab) & 2.65 & 13.77 & 26.37 & 1.16 \\
\hline $\begin{array}{l}\text { Respects Haitian autonomy } \\
\text { (Rèspekte otonomi ayisyen) }\end{array}$ & 1.10 & 3.75 & 66.13 & 16.10 \\
\hline $\begin{array}{l}\text { Helping Haiti be a peaceful place } \\
\text { (Ap ede ayiti vin yon andwa ki pi } \\
\text { pezib) }\end{array}$ & 1.23 & 2.84 & 38.14 & 2.39 \\
\hline $\begin{array}{l}\text { Communicates effectively } \\
\text { (Kominike avèk efikasite) }\end{array}$ & 1.62 & 28.64 & 13.25 & 35.36 \\
\hline Approachable (Aksesib) & 6.53 & 5.56 & 33.87 & 5.75 \\
\hline Competent (Konpetan) & 30.06 & 12.29 & 9.44 & 7.76 \\
\hline $\begin{array}{l}\text { Worthy of my respect } \\
\text { (Diy de respè w) }\end{array}$ & 1.49 & 2.19 & 28.83 & 7.69 \\
\hline $\begin{array}{l}\text { Considerate of local concerns } \\
\text { (Konsidere enkyetid lokal) }\end{array}$ & 2.46 & 4.65 & 28.18 & 2.52 \\
\hline $\begin{array}{l}\text { Cares about the Haitian people } \\
\text { (Pran swen pèp ayisyen an) }\end{array}$ & 0.45 & 2.91 & 27.28 & 9.05 \\
\hline $\begin{array}{l}\text { Represents the interests of people } \\
\text { like me (Reprezante enterè moun } \\
\text { tankou } m \text { ) }\end{array}$ & 8.66 & 9.44 & 25.86 & 25.15 \\
\hline Reliable $(F y a b)$ & 5.04 & 22.56 & 6.33 & 24.89 \\
\hline Honest (Onèt) & 1.75 & 1.23 & 22.75 & 0.90 \\
\hline $\begin{array}{l}\text { Here to assist us (La pou asiste } \\
\text { nou) }\end{array}$ & 2.33 & 4.52 & 19.33 & 8.66 \\
\hline Empowering (Ankourajan) & 2.71 & 2.59 & 17.91 & 3.17 \\
\hline $\begin{array}{l}\text { Respects the opinions of people } \\
\text { like me (Rèspèkte opinyon moun } \\
\text { tankou m) }\end{array}$ & 5.17 & 8.34 & 16.42 & 16.22 \\
\hline $\begin{array}{l}\text { Believes that ordinary Haitian } \\
\text { people can solve Haiti's problems } \\
\text { (Kwè ke moun òdinè ayisyen kapab } \\
\text { rezoud pwoblèm ayiti) }\end{array}$ & 1.49 & 11.12 & 12.09 & 5.43 \\
\hline Trustworthy (Diy konfyans) & 5.30 & 6.59 & 9.44 & 2.39 \\
\hline \multicolumn{5}{|c|}{$\begin{array}{l}\text { Note: \% out of total number of respondents; } \mathrm{N}=1,547 \text {, sample dropped to only include } \\
\text { respondents who evaluated all four types of organizations; original (Haitian Creole) wordings in } \\
\text { italics; highest percentage per row in bold. Respondents were allowed to provide positive } \\
\text { responses to multiple indicators, so column and row totals do not add up to } 100 \% \text {. }\end{array}$} \\
\hline
\end{tabular}




\section{Figure 1: Positive and Negative Assessment of Survey Wording}

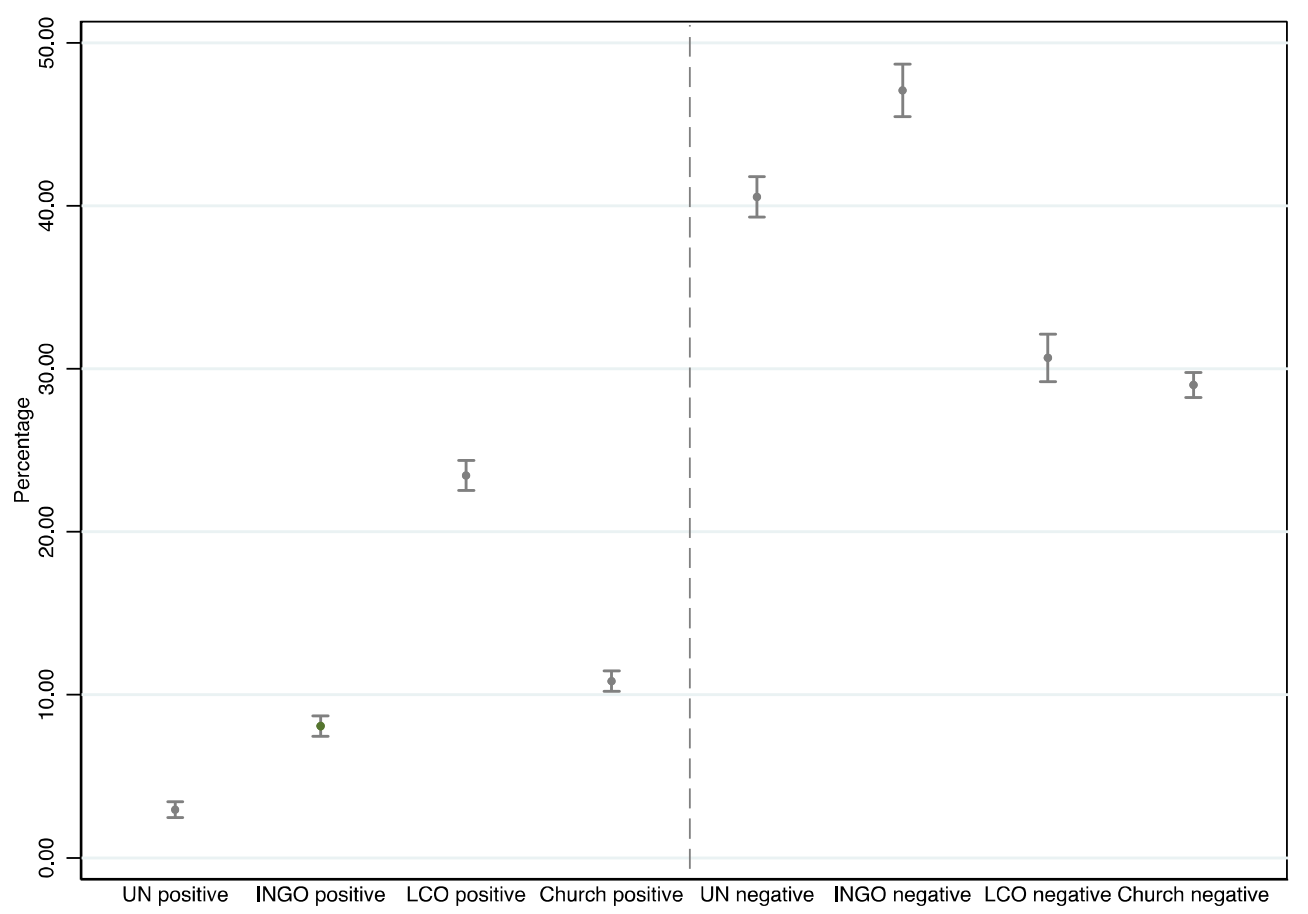

Note: $\mathrm{N}=1,547$; vertical bars show confidence intervals calculated at $99 \%$

\footnotetext{
${ }^{1}$ In this symposium, Levy and Firchow (2021) accordingly propose multiple iterations to scale up from initial focus groups informing about local communities to higher, more encompassing levels of analysis.

${ }^{2}$ The selection of organization is based on a. not being involved in scandals; b. delivering quick-impact projects; c. widely known to Haitian citizens across the country.

${ }^{3}$ Open-ended questions give complete freedom to the respondents, but they are often less informative than hoped. Respondents may decide to limit their responses to what comes immediately to mind or neglect to mention indicators they consider to be self-evident (Bruine de Bruin et al. 2011).
} 